\title{
Tratamento cognitivo-comportamental para o transtorno de pânico e agorafobia: uma história de 35 anos
}

\author{
Cognitive-behavioral therapy for panic disorders and \\ agoraphobia: 35 years of history
}

Bernard RANGÉ

\begin{abstract}
Resumo
Este artigo descreve a evolução do conhecimento sobre um tratamento cognitivo-comportamental do transtorno de pânico e da agorafobia. É baseado em contribuições de vários pesquisadores e descrito como um tratamento integrativo na medida em que associa tratamento farmacológico e vários tipos de intervenções cognitivas e comportamentais. Utiliza técnicas de reestruturação cognitiva, habituação interoceptiva, técnicas respiratórias, de exposição situacional e reestruturação existencial. 0 tratamento foi originalmente desenvolvido para atendimentos individuais, mas depois foi também utilizado para atendimentos em grupo. Foi concebido para ser um atendimento que pudesse ser desenvolvido por terapeutas que trabalhassem em locais onde não existisse uma terapia cognitivo-comportamental qualificada, em um modelo de tratamento passo-a-passo. Os resultados têm sido muito satisfatórios, com exceção de algumas intervenções, como o treinamento em assertividade e o relaxamento muscular. Ajustes foram realizados para atender esses achados.
\end{abstract}

Unitermos: Agorafobia. Terapia cognitivo-comportamental. Transtorno de pânico.

\begin{abstract}
This paper describes the evolution of knowledge of cognitive-behavioral treatment of panic disorder and agoraphobia. It is based on contributions by diverse researchers, and it is described as an integrative treatment inasmuch as it combines pharmacological treatment and various types of cognitive and behavioral therapies. It uses cognitive restructuring techniques, interoceptive habituation, techniques for breathing, situational exposure and existential restructuring. The treatment was originally developed for an individual approach, but it was also later used with group treatments. It was conceived as a treatment to be used by therapists working in places where it would not be possible find qualified cognitive-behavioral treatment, in a step-by-step treatment model. Results have been most satisfactory with the exception of some interventions such as assertiveness training and muscular relaxation. Adaptations were made to cater to these findings.
\end{abstract}

Uniterms: Agoraphobia. Psychotherapists. Panic disorder.

Meu primeiro cliente, ICC, apresentou-se com um quadro que, naquele longínquo ano de 1972, era chamado de "neurose de angústia", mas que hoje seria classificado como Transtorno de Pânico (TP) com
Agorafobia (AGO) (American Psychiatric Association APA, 2002). Seu primeiro ataque de pânico ocorreu quando estava em um ônibus que vinha de Petrópolis para o Rio de Janeiro, vindo da casa de seus pais, que

$\nabla \nabla \nabla \nabla$

1 Universidade Federal do Rio de Janeiro, Instituto de Psicologia, Programa de Pós-Graduação em Psicologia. R. Visconde de Pirajá, 547, Sala 608, Ipanema, 22410-900, Rio de Janeiro, RJ, Brasil.E-mail: <bernard.range@gmail.com>. 
passavam uma temporada de férias naquela cidade. Os seus sintomas consistiram em uma forte taquicardia, sensações de falta de ar, tontura, ondas de frio e calor, sudorese, tremores internos e idéias de morte iminente por ataque cardíaco. Em decorrência disso, passou a evitar andar de ônibus, elevador, avião, passar em túneis e viadutos, e evitava também engarrafamentos. Isto teve como implicação a contratação de um sócio para trabalhar em sua empresa, uma vez que ela prestava serviços em outros locais do Brasil, notadamente São Paulo, Salvador, Belo Horizonte e Curitiba. Seus deslocamentos pela cidade do Rio de Janeiro eram feitos em horários muito cedo ou muito tarde, para evitar os previsíveis engarrafamentos que, já naquela época, ocorriam. Por sorte o seu escritório era no primeiro andar, mas, às vezes, clientes Ihe solicitavam que fosse ao escritório deles, que com freqüência eram em andares acima do 250, e mesmo assim ele ia de escada. Ele só se sentia bem dirigindo o seu próprio carro e, assim, fazia viagens longas para os lugares mais próximos, como São Paulo ou Belo Horizonte, ao invés de usar avião. Mesmo assim, os negócios não estavam indo tão bem, porque o sócio não se dedicava com esforço adequado. Ele não agüentava mais ter ataques e limitações em sua vida. Era uma pessoa muito alegre, agradável e divertida, mas seu sofrimento parecia ser intenso.

Desde essa época interessei-me pelo tratamento desses quadros. Como aluno ainda, eu já havia começado a minha formação em terapia comportamental. Tenho gratidão por dois grandes mestres que tive. Um, infelizmente, faleceu precocemente: Octávio Soares Leite. Era um estudioso insaciável, que conhecia desde as últimas novidades no campo da psicologia experimental até as contribuições mais recentes sobre Carl Gustav Jung. Nessa época, sobretudo no Rio de Janeiro, por influência de um velho amigo, Geraldo Lanna, a terapia comportamental era chamada de "condutoterapia", e as primeiras informações que tive sobre trabalhos nessa área vieram de uma aula de Octávio sobre a dessensibilização sistemática de Joseph Wolpe, em um curso que ele ministrava sobre Aprendizagem Humana, em 1969. Ao final da aula, ao comentar que havia gostado do que ele havia exposto, mas tinha dúvidas sobre a funcionabilidade daquele procedimento, ouvi dele o melhor conselho que já tive: "Se 478 você tem dúvidas, teste!".
Foi assim que começou a surgir, no Rio de Janeiro, um grupo de pessoas interessadas em terapia comportamental, rodeadas em torno de Octávio. Pouco depois, começou a fazer parte do grupo uma outra professora, que acabava de chegar de um treinamento de um ano com o próprio Wolpe, na Temple University. Esta foi minha segunda grande mestra. Infelizmente foi por pouco tempo, pois foi morar em São Paulo, onde vive até hoje. Ela supervisionava os aspectos práticos no grupo orientado por Octávio.

Afastando-me um pouco destas agradáveis recordações, voltemos ao caso ICC. Meus estudos informaram que o conhecimento na época não validava tratamentos baseados na dessensibilização sistemática para quadros de agorafobia: o tratamento efetivo era a exposição gradual ao vivo, com o objetivo de produzir uma extinção da resposta de medo (Gelder \& Marks, 1966). Assim começou o meu interesse na área de pânico e agorafobia.

Minha dissertação de mestrado versou sobre assuntos novamente discutidos nas aulas de Octávio Leite: evidências empíricas que estremeciam os fundamentos teóricos da teoria bifatorial de Mowrer como explicação para a esquiva e os quadros fóbicos.

Em 1991, houve um Congresso Brasileiro de Psiquiatria em Maceió, no estado de Alagoas, para o qual eu havia sido convidado para dar um curso de três aulas sobre terapia cognitiva. Na semana anterior, eu havia atendido pela primeira vez um dos casos mais graves de transtorno de pânico que eu já havia acompanhado até então: esta mulher tinha vários ataques de pânico por dia. Sendo assim, após entrevistá-la, constatar o seu problema e explicar-lhe os seus mecanismos de ação, encaminhei-a para uma psiquiatra amiga minha, doutora Vera Lemgruber, que atende alguns andares acima, no mesmo prédio que eu, para que ela fosse medicada. Combinamos que ela voltaria na semana seguinte. Nesta semana, ela já havia sido recebida pela psiquiatra, que a avisara que estaria em um congresso a partir do dia seguinte. Quando ela chegou ao meu consultório, eu também a avisei que estaria no mesmo congresso, e também a partir do dia seguinte. Ela se sentiu muito desamparada e, aflita, perguntou se eu não tinha nada escrito para ajudá-la. Prometi a ela que o faria durante o vôo. Foi assim que surgiu a "Estratégia A.C.A.L.M.E.-S.E.". Ao chegar ao hotel, datilografei-a em uma máquina de escrever para enviar-lhe por fax (Rangé, 1995). 
Em 1993, ocorreu um Congresso Mundial de Psiquiatria no Rio de Janeiro. Graças à minha amizade com a doutora Vera, consegui ter acesso aos resumos enviados e pude descobrir a vinda de David Barlow, Samuel Turner, Jack Maser, Joseph Wolpe, Rafael Navarro Cuevas, Gualberto Buela-Casal, Vicente Caballo, Herbert Chappa, Sergio Pagés e Hector Fernandez-Alvarez. De conversas com David Barlow e Jack Maser surgiram informações fundamentais para o crescimento do meu conhecimento sobre transtorno de pânico e agorafobia. De conversas com Herbert Chappa, Sergio Pagés e Hector Fernandez-Alvarez surgiu uma amizade, que é um dos motivos de eu estar aqui escrevendo.

Motivos de ordem pessoal atrasaram o início de meu doutorado, que só pôde começar em 1994, depois de meu ingresso na Universidade Federal do Rio de Janeiro. Depois de cursar várias disciplinas e em conversas com meu orientador sobre o que eu gostaria de escrever como tema da minha tese, ele me relatou que outro orientando dele tinha feito uma pesquisa baseada em um programa de rádio, em que ele apresentava informações para a população que o ouvia. Tive, então, a idéia de desenvolver um protocolo de tratamento para o transtorno de pânico e a agorafobia para ser utilizado por pessoas que não tivessem um treinamento específico em terapia cognitivo-comportamental (TCC). Isso ocorreu porque eu estava, naquele ano de 1996, dando cursos de TCC em Goiânia, e havia desenvolvido um protocolo integrativo (tratamento farmacológico, terapia cognitiva, terapia comportamental, terapia racional-emotiva-comportamental) que estava sendo utilizado pelos meus estagiários na Divisão de Psicologia Aplicada (DPA) do Instituto de Psicologia (IP) da Universidade Federal do Rio de Janeiro (UFRJ). Uma das alunas era psicóloga clínica com formação em "psicodinâmica" e interessou-se em testar o protocolo com três de seus clientes. Os resultados que ela obteve, medidos por diversos inventários, foram muito bons.

Decidi, durante os anos de 1997 e 1998, aprimorálo, até que alcançou a forma final, denominada Vencendo o pânico: programa de tratamento multicomposto específico para o transtorno de pânico e a agorafobia, em duas versões: uma para terapeutas não treinados em TCC e outra para pacientes. Esse protocolo foi utilizado pelos meus estagiários da seguinte forma: eu entregava impressos para eles lerem e usarem com seus pacientes com Transtorno de Pânico e Agorafobia. Eventualmente, eles faziam relatos sobre como estavam ocorrendo os atendimentos, mas eu não dava supervisão. Os pacientes recebiam também o material deles, a cada sessão, para lerem e exercitarem em casa as tarefas indicadas. Estava concebido inicialmente para ser um protocolo para uso em casos individuais, em sessões de hora e meia, em função da quantidade de tarefas para fazer em cada sessão. Posteriormente foi utilizado também para atendimentos em grupo.

Tudo começou com uma pesquisa de David Clark citada no livro de Seligman (1995), em que, para um grupo de 20 pacientes com TP, divididos em dois grupos de dez, ele apresentou para um dos grupos a seguinte frase: "O lactato é uma substância corporal natural que produz sensações semelhantes ao exercício ou ao álcool. É normal sentir intensas sensações durante a infusão, mas elas não indicam uma reação adversa", e para o outro grupo nada foi informado. Essa substância foi administrada e, dos dez pacientes do primeiro grupo, apenas três tiveram ataques de pânico; dentre aqueles que nada sabiam, nove tiveram os ataques (p.71). Isso demonstrava com clareza a importância das informações para quem tem ataques de pânico.

Ao mesmo tempo, entrei em contato com o livro de Wolfe e Maser (1994), Treatment of panic disorder: A consensus development conference, que representava o relatório de uma conferência realizada em 1991, promovida pelo Instituto Nacional de Saúde Mental dos Estados Unidos, visando ao estabelecimento de um consenso entre os 25 especialistas das mais diferentes áreas do conhecimento sobre Transtorno de Pânico e Agorafobia convidados para esse encontro. Um resumo deste relatório pode ser encontrado abaixo:

\section{Conferência do National Institute of Mental Health (NIMH)}

- A TCC é um tratamento efetivo para o TP, variando entre $74 \%$ e $95 \%$ o seu grau de eficácia, medida em termos de ausência de ataques de pânico depois de três meses de tratamento, e com os ganhos se mantendo de modo consistente depois de seguimentos de um e dois anos.

- Tanto a resposta imediata quanto a de longo termo comparam-se favoravelmente em relação a tratamentos alternativos, como imipramina e relaxamento aplicado. 
- A taxa de recaída é significativamente menor do que com a imipramina.

- A análise de componentes indica que os efeitos operam por mudança cognitiva e extinção interoceptiva e exteroceptiva.

- Há evidências de eficácia com apenas 3,5 horas de contato com um terapeuta, complementadas com biblioterapia.

- Tratamentos combinados (exposição mais imipramina ou alprazolam) indicam eficácia de curto prazo de 66\% - 76\% para TP com agorafobia, com pequena vantagem para exposição mais imipramina, do que exposição, imipramina ou alprazolam sozinhos.

- Tratamentos combinados (exposição mais imipramina ou alprazolam) indicam eficácia de longo prazo de 50\% - 75\% em seguimentos de um ou dois anos, mas a combinação de exposição mais imipramina não se mostrou mais efetiva do que exposição apenas.

- O uso combinado de exposição e alprazolam mostra resultados de longo prazo piores e maior taxa de recidiva do que exposição apenas.

- Os resultados não recomendam o uso de tratamentos combinados, a não ser quando:

1. não houver TCC disponível;

2. ela não for aceita pelo paciente;

3. uma TCC adequada não tenha mostrado bons resultados;

4. houver a presença de outros problemas (p.ex., depressão).

A declaração consensual destacou que:

- O transtorno de pânico é uma condição distinta, com uma apresentação, curso específico e história familiar positiva, para a qual existem tratamentos farmacológicos ou cognitivo-comportamentais efetivos.

- Tratamentos que falham em produzir resultados em seis ou oito semanas devem ser reavaliados.

- Pacientes com transtorno de pânico, com freqüência, têm uma ou mais condições comórbidas que requerem avaliação e tratamento cuidadoso.

- As necessidades mais críticas de pesquisa são:

- Desenvolvimento de medidas confiáveis, válidas e estandartizadas para avaliação e resultados;
- Identificação de escolhas ótimas e estruturação de tratamentos desenhados para atender às necessidades individuais variadas de cada paciente;

- Implementação de pesquisa básica para definir a natureza do transtorno.

- Barreiras para o tratamento incluem conhecimento, acessibilidade e recursos.

- Uma campanha educacional agressiva para aumentar a consciência desses temas deve ser montada para clínicos em geral, pacientes e suas famílias, para a mídia e para o público em geral.

Sublinhei os trechos que pareciam mais pertinentes aos meus objetivos, apesar de o último, hoje em dia, já não ser tão verdadeiro. Os outros três sublinhados e todas as outras informações descritas eram muito importantes.

Esse material fundamentou o meu protocolo Vencendo o Pânico: Programa de Tratamento Multicomposto Específico para o Transtorno de Pânico e a Agorafobia. Ele é constituído de oito sessões (a primeira versão era constituída de seis sessões) de tratamento cognitivocomportamental, com duas sessões de avaliação inicial, mais uma bateria de escalas a ser preenchidas em casa; e ainda uma reavaliação das escalas ao final da penúltima sessão, que novamente os pacientes levavam para preencher em casa.

Nas sessões de avaliação são aplicadas as entrevistas estruturadas Anxiety Disorders Interview Schedule for DSM-IV (ADIS-IV): Entrevista Estruturada para os Transtornos da Ansiedade para o DSM-IV (Di Nardo, Brown \& Barlow, 1995), e a Structured Clinical Interview forDSM - Personality Disorders (SCID-TP): Entrevista Clínica Estruturada para o DSM, versão para Transtornos da Personalidade (Pfohl, Zimmerman, Blum \& Stangl, 1989), além de uma variedade de testes, escalas e inventários que os pacientes levam para casa para preencher: Questionário de Pânico (Rangé, 1996) e de Crenças de Pânico (Wenzel, Sharp, Brown, Greenberg \& Beck, 2006), Inventários Beck de Depressão (Beck, Ward, Mendelson, Mock \& Erbaugh, 1961) e de Ansiedade (Beck, Eptein, Brown \& Steer, 1988), Inventário de AnsiedadeTraçoEstado (IDATE) (Biaggio, Natalicio \& Spielberger, 1977), Escala de Sensações Corporais e Escala de Cognições Agorafóbicas (Chambless, Caputo, Bright \& Gallagher, 
1984), Inventário de Mobilidade (Chambless, Caputo, Gracely \& Williams, 1985), Symptom Checklist-90 Revised (SCL-90) (Derogatis, Lipman \& Covi 1973) e Escala Brasileira de Assertividade (Ayres \& Ferreira, 1995). Essas escalas são reaplicadas no pós-teste e nos segui-mentos. Com as reformulações realizadas, as escalas também foram modificadas. Saíram as escalas IDATE e SCL-90 e entraram as seguintes escalas: Escala de Pânico e Agorafobia (Bandelow, 1995); e escala SF-36 (Ciconelli, Ferraz\& Santos, 1998).

A primeira sessão de tratamento tem como objetivos estabelecer um rapport, oferecer informações básicas sobre o problema e o seu tratamento, coletar informações complementares e estabelecer metas. Ao final desta sessão, os clientes levam um texto referente ao primeiro passo do programa de tratamento, que inclui informações sobre o Transtorno de Pânico e a Agorafobia, sobre o modelo cognitivo dessas perturbações e sobre o tratamento dele derivado, além de textos com informações sobre a fisiologia e a psicologia do medo e da ansiedade e a fisiologia da hiper-respiração. Com essas informações, o paciente já chega à segunda sessão entendendo um pouco mais o que se passa com ele (Baillie \& Rapee, 2004).

A segunda sessão tem como objetivos treinar habilidades de manejo. As metas e tarefas da sessão incluem:

1. Introduzir a Estratégia A.C.A.L.M.E.-S.E.

2. Fazer hiperventilação no passo 4 do A.C.A.L.M.E.-S.E.

3. Introduzir o treino respiratório com a respiração diafragmática ao final do exercício.

4. Introduzir a estratégia de Situações, Pensamentos Automáticos, Emoções e Comportamento (SPAEC).

5. Verificar se o paciente compreendeu claramente as relações das seqüências SPAEC.

6. Treinar o preenchimento dos Registros Diários de Pensamentos Disfuncionais (RDPD) e a folha do SPAEC.

As instruções para a Estratégia A.C.A.L.M.E.-S.E. (Rangé, 1995) exigem que ela seja lida em voz alta pelo paciente, com o terapeuta interrompendo freqüente- mente para ressaltar, sublinhar e explicar detalhadamente cada aspecto.

O primeiro aspecto importante a ressaltar diz respeito à aceitação das sensações. O cliente já leu nos textos que essas sensações são apenas sinais de ansiedade ou de uma ativação simpática, que é uma reação primitiva de luta-ou-fuga necessária para a sobrevivência dos organismos em situações de perigo, ou em situações em que ele pensa que está em perigo. Com essa informação, ele entende que essas sensações podem até ser desagradáveis, mas não são perigosas. Mesmo o aspecto de desagradabilidade é discutível, pois, na atividade sexual, podem-se sentir muitas dessas sensações e achá-las agradáveis. Tudo depende do contexto em que são avaliadas; daí ser perfeitamente aceitável experimentá-las.

Outro aspecto importante diz respeito à idéia de que essas sensações parecem antecipações de "perigos" (morrer sufocado ou de ataque cardíaco, perder o controle, ficar louco, desmaiar). Na verdade não são antecipações, são conseqüências dos pensamentos que o indivíduo tem a partir de suas sensações. E a maior evidência disso é que nunca foram ou são confirmadas.

Cada letra da palavra A.C.A.L.M.E.-S.E. representa um passo necessário para o manejo adequado de uma situação percebida como ameaçadora, como a iminência de novas sensações corporais.

O paciente leva para casa uma cópia da Estratégia A.C.A.L.M.E.-S.E. e duas cópias das folhas de Registro de Pensamentos (Beck, 1997). Nas sessões, todos esses registros são revisados com o terapeuta.

A sessão 3 tem como objetivo provocar uma conscientização corporal e fortalecer o treino de restruturação cognitiva. Suas principais metas e tarefas são:

1. Análise dos RDPDs: rever registros (se houver), fazendo as devidas correções sobre a forma de registrar pensamentos automáticos (PA), se necessário. Ex:."vou cair, ao invés de "vontade de fugir". Solicitar que o paciente analise os PAs em seu registro, e propor "respostas (racionais) alternativas".

2. Fazer os exercícios de exposição interoceptiva para produzir uma habituação às sensações (Barlow \& Cerny, 1999).

3. Iniciar um exercício de relaxamento. Caso o paciente resista ao exercício (movendo-se, falando, mantendo os olhos abertos, desobedecendo instruções 
etc.) ou dê sinais de intensa ansiedade, interromper o exercício e solicitar novos RDPDs incluindo respostas racionais.

4. Solicitar treino em relaxamento como tarefa para casa, mais treino respiratório.

A sessão inicia-se com a revisão dos registros de pensamento. Os registros são completados, incluindo também as respostas racionais e o prenchimento da coluna de reavaliação.

A seguir, o treino de habituação interoceptiva (Barlow \& Cerny, 1999) é iniciado com uma explicação da lógica do condicionamento interoceptivo e como ela se aplica a ataques de pânico. $\mathrm{O}$ argumento básico consiste no fato de que as sensações iniciais de ansiedade tendem a ficar associadas às sensações finais (isto é: o próprio ataque de pânico) por meio de um condicionamento pavloviano. Dessa forma, as sensações iniciais podem disparar, sem mediação cognitiva, novos ataques de pânico. Por essa razão, ataques de pânico podem ocorrer à noite, quando as pessoas estão dormindo e pensando em nada. O terapeuta deve solicitar que o paciente realize os exercícios abaixo conforme descritos e anotar nas colunas correspondentes as avaliações feitas pelo paciente. Deve solicitar também que o paciente os faça uma vez por dia em casa (e em outros locais que ele considere seguros), anotando os resultados das sensações nas colunas correspondentes. Os resultados de intensidade da sensação e de similaridade se mantêm, mas os resultados de ansiedade costumam cair. Nas sessões subseqüentes, deve-se solicitar que o paciente estabeleça uma hierar- quia de situações reais em que se produzam sensações equivalentes (p.ex:: montanha russa, caminhadas, nadar, dançar, exercícios em bicicletas ergométricas de academias de ginástica), para que o paciente venha a se expor progressivamente a cada uma delas (Tabela 1).

No que diz respeito ao relaxamento muscular progressivo (Jacobson, 1938) deve-se apenas fazer o exercício no paciente, chamando a atenção dele para a concentração necessária para discriminar a diferença entre graus variados de tensão nos diversos músculos do corpo. É importante também destacar a importância que o relaxamento muscular tem para produzir um relaxamento periférico que, por sua vez, induz um estado de relaxamento mais central, representado pela ativação do sistema parassimpático. É importante acrescentar sugestões, como são feitas no treinamento autógeno (Luthe, 1969) e incentivar a visualização de cenas traquilizadoras, como uma praia deserta ou a relva de uma montanha, com seus odores e brisas.

Os objetivos da sessão 4 são os de fortalecer a auto-eficácia. As seguintes metas e tarefas são almejadas:

1. Análise dos RDPD, com respectivas correções, se necessárias.

2. Fazer hierarquia de exposições situacionais (para pacientes que também tenham Agorafobia).

3. Iniciar exposição gradual ao vivo, ressaltando o uso da estratégia A.C.A.L.M.E.-S.E. por meio da aceitação das sensações, treino respiratório e restruturação por meio dos RDPD.

4. Solicitar preenchimento de curtograma² e lista de desejos.

Tabela 1. Exercícios de exposição interoceptiva para pacientes.

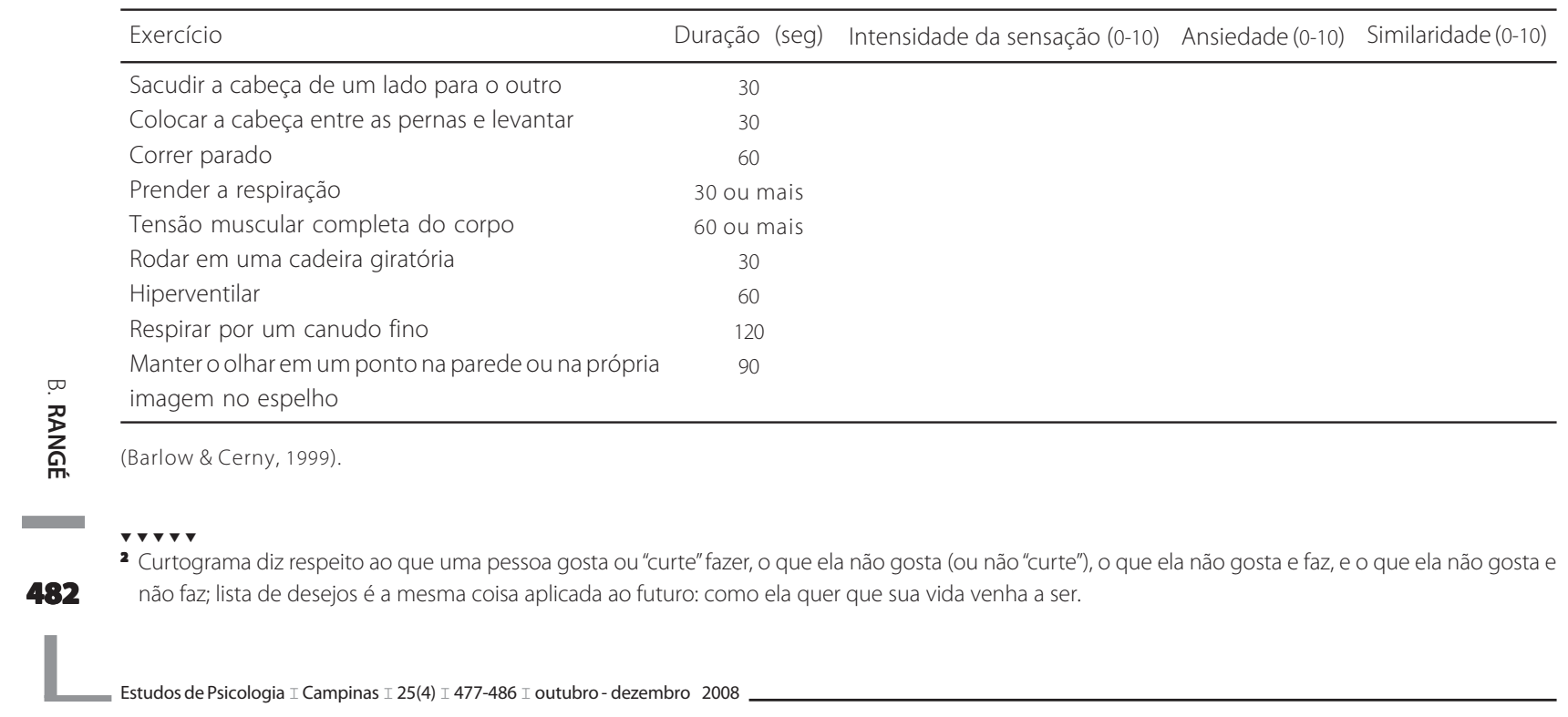


5. Solicitar treino em relaxamento.

6. Recomendar novos exercícios graduais de auto-exposição como tarefa de casa.

Esta sessão é para pacientes que, além de TP, também preenchem critérios diagnósticos para Agorafobia. Se o paciente não tiver problemas de deslocamento solitário, a quinta e a sexta sessão serão desenvolvidas nesse momento. Se ele tiver, deve-se fazer uma hierarquia de exposições, conforme exemplo abaixo. Depois de construída, começar junto com o paciente pelo item mais baixo e subir progressivamente. Este exercício deve ser feito com exposição prolongada, isto é, só se passa para o item seguinte quando a ansiedade experimentada em um determinado item for desprezível. O rebaixamento da ansiedade pode durar mais de meia hora, mas pode ser muito menor. Deve-se avaliar ou pedir ao paciente para avaliar (conforme o estágio na hierarquia) a quantidade de ansiedade, em graus subjetivos, em uma escala imaginária de 0 a 100.

Exemplo de uma de Hierarquia de Exposições:

1. Distanciar-se uma quadra;

2. Dar uma volta no quarteirão;

3. Dar uma volta em dois quarteirões (o terapeuta vai antes e espera no final);

4. Caminhar por x quarteirões sem a presença do terapeuta (ou outra pessoa);

5. Pegar um táxi até a própria casa (dependendo da distância, trajeto com túneis, engarrafamentos ou não);

6. Andar em um elevador (um andar ou mais);

7. Pegar um ônibus (um ponto ou mais);

8. Andar de metrô (uma estação ou mais).

O objetivo da sessão 5 é tentar favorecer uma modificação na forma como cada cliente maneja a sua existência. As seguintes metas e tarefas fazem parte dela:
1. Análise dos RDPD, com respectivas correções, se necessário.

2. Introduzir a noção de Hedonismo Responsável.

3. Discutir a crença irracional de Albert Ellis (1962): "É absolutamente necessário para mim ser admirado ou amado pelas pessoas que me são importantes".

4. Introduzir a noção de assertividade, fazendo também uma dramatização de uma das situações negativas.

5. Tarefas para casa: a) preencher RDPD; b) satisfazer itens do curtograma; c) satisfazer itens da lista de desejos; d) Treinar relaxamento muscular; e) fazer auto-exposições.

Deve-se discutir, neste momento, a noção de hedonismo responsável (Dryden \& Ellis, 1988), entendida como a idéia de que somos movidos por desejos, mas que isso só se justifica se for feito de forma racional, isto é, em que se avalie as implicações positivas e negativas de curto, médio e longo prazo de cada decisão, caso contrário poderíamos agir impulsivamente e nos arrepender de nossas decisões. Deve-se discutir também em que medida uma (ou mais) das próximas três crenças possam estar sendo seguidas pelo paciente (Tabela 2).

O conceito de assertividade ou de afirmação pessoal refere-se à expressão direta, honesta e adequada de sentimentos, acompanhada dos comportamentos correspondentes (Martins, 2005). Já foi visto que pacientes com pânico são pouco assertivos (Chambless, Hunter \& Jackson, 1982). Pode-se compreender isto por seu temor de serem reprovados. Um certo tempo das sessões 5 e 6 deve ser ocupado com uma análise das situações em que o paciente não consegue ser assertivo e com o treinamento de habilidades de assertividade.

Treinar habilidades de afirmação diz respeito a ensinar a agir desta forma. Uma afirmação é um pensamento positivo que escolhemos para expressá-la, para que assim possamos atingir um objetivo. A maior força de uma pessoa virá primeiramente do modo como ela

Tabela 2. Crenças irracionais (Ellis, 1962).

\footnotetext{
1. A idéia que existe uma extrema necessidade para qualquer ser humano adulto ser amado ou aprovado virtualmente por qualquer outra pessoa significativa em sua comunidade;

2. A idéia de que se deve ser inteiramente competente, adequado e realizador em todos os aspectos possíveis, para se considerar dotado de valor;

3. A idéia que é terrível e catastrófico quando as coisas não são do jeito que a gente gostaria que fossem.
} 
afirma seu valor como pessoa. Existem duas formas de afirmações que ela poderia explorar: a primeira são crenças particulares referentes a quem ela é; e a segunda são crenças referentes às coisas que ela quer fazer em sua vida.

A sessão 6 tem como objetivo básico a manutenção e o fortalecimento do que foi aprendido. As metas e tarefas:

1. Rever e analisar tarefas.

2. Discutir a crença irracional de Albert Ellis (1962): "Devo ser inteiramente competente, adequado e realizador em todos os aspectos possíveis para me considerar como tendo valor".

3. Discutir a crença irracional de Albert Ellis (1962): "É terrível e catastrófico quando as coisas não são do jeito que a gente gostaria muito que fossem".

4. Análise de iniciativas existenciais.

5. Repetir exercícios de relaxamento, de conscientização corporal e respiratórios.

6. Despedidas.

O pós-teste consiste em reavaliar o desempenho nas escalas aplicadas anteriormente. O objetivo é avaliar o status do paciente em relação a níveis de ansiedade, depressão, evitações, assertividade e funcionamento global na vida.

Uma das primeiras mudanças foi adaptar o protocolo para tratamentos em grupo. O número original era de seis sessões. Considerando que nos grupos talvez existissem pessoas com menor qualificação de entendimento, aumentei então o protocolo para oito sessões. Houve uma diminuição de tarefas em cada sessão, e uma distribuição mais adequada naquelas ocorrendo a partir da quarta sessão. $O$ treino assertivo, que não apresentava resultados satisfatórios, teve a sua duração aumentada, com as atividades distribuídas em quatro sessões ao invés de apenas uma. A restruturação existencial ficou dilatada para três sessões. A exposição situacional foi ampliada para quatro sessões.

Assim, a sessão 4 passou a ter como objetivo o fortalecimento da auto-eficácia, na medida em que se iniciaria a exposição situacional. As principais metas e tarefas nessa sessão seriam, em primeiro lugar, construir uma hierarquia inicial para exposições situacionais e fazer uma primeira exposição usando as habilidades de 484 manejo da ansiedade já adquiridas. Em segundo lugar, começaria a discussão da crença irracional "É absolutamente necessário para mim ser amado e aprovado pelas pessoas que me são importantes. O combate desta crença favoreceria o fortalecimento da auto-estima e da independência. Para terminar, a sessão envolveria também o início do treino assertivo, com exercícios envolvendo elogiar e ser elogiado. Como tarefas de casa, o indivíduo deve continuar a fazer exercícios de relaxamento respiratório e muscular, preencher RDPD e elogiar outras pessoas.

A sessão 5 continuou a ter como primeiro objetivo a restruturação existencial, isto é, como o paciente conduz a própria vida em termos de exigências consigo próprio e de não tolerar as sensações desconfortáveis da ansiedade. Nesta sessão, além de continuar a fazer exposições a situações ansiogênicas, ele deve ser capaz de aprender a dizer não para solicitações inadequadas de outros. É introduzida a noção de"hedonismo responsável" e discutida outra crença irracional de Ellis: "Devo ser inteiramente competente, adequado e realizador em todos os aspectos possíveis para poder me considerar como tendo valor." Como tarefas para casa, são solicitados um curtograma, auto-exposições e o exercício de dizer não para outras pessoas.

A sessão 6 envolve uma segunda parte do manejo existencial, em que é analisado o curtograma e incentiva-se o cliente a fazer mais o que "gosta mas não faz". É também instado a fazer mais exposições situacionais da hierarquia construída. Quanto ao treino em assertividade, é exercitada a terceira parte: pedir coisas ou ajuda de outros. Há também uma discussão da terceira crença irracional de Ellis: "É terrível e catastrófico quando as coisas não acontecem do jeito que eu queria." Como tarefas para casa, são solicitados o preenchimento de uma lista de desejos, a continuação das auto-exposições e pedir coisas ou ajuda para outras pessoas.

A sessão 7 envolve mais uma sessão de manejo existencial. Solicita-se que o individuo faça mais exposições situacionais da hierarquia. Além disso, verifica-se se o cliente tentou fazer mais coisas que lhe dessem prazer, como indicado no curtograma, e analisa-se a sua lista de desejos, incentivando o planejamento de um futuro realizador e feliz. Quanto ao treino em assertividade, é realizada a quarta parte, que envolve pedir mudanças no comportamento dos outros. As tarefas para casa incluem continuar a fazer auto-exposições, pedir mudanças no comportamento de outras 
pessoas e solicitar que tragam os questionários do pós-teste e as avaliações preenchidas sobre o trabalho realizado.

A sessão 8 é a de encerramento. O objetivo desta sessão é fortalecer estratégias de manutenção e de prevenção de recaídas. Para isso, são revisadas e analisadas as iniciativas em relação ao curtograma e aos desejos, aos pedidos para outras pessoas mudarem seus comportamentos, ao preenchimento de RDPDs etc. São feitos novamente exercícios de relaxamento muscular e respiratório e de exposição interoceptiva. Informações para prevenir recaídas são oferecidas e tudo o que foi examinado durante o tratamento é revisto, para que possa existir uma manutenção do que foi aprendido e evitá-las. Uma avaliação do trabalho feito, incluindo ganhos com o tratamento, dificuldades e sugestões, é parte importante desta sessão. São feitas então as despedidas.

A partir de novas investigações empíricas, houve algumas modificações no protocololo original.

No protocolo anterior, havia uma sessão dedicada ao relaxamento muscular e recomendações para que esta atividade fosse exercitada em casa. Considerando que nesta tarefa, diferentemente de outras (que implicavam os pacientes trazerem algo produzido, por exemplo, um registro de pensamentos preenchido ou uma folha de registro de habituação interoceptiva), cabia apenas ao paciente informar se tinha feito ou não o exercício. Talvez alguns até tivessem feito, mas provavelmente a maioria não. Como já tínhamos muitos dados de tratamentos individuais e em grupo com relaxamento muscular, fizemos quatro grupos sem relaxamento muscular, para comparar os resultados. Não houve diferenças significativas entre tratamento com e sem relaxamento muscular.

Os dados de pós-teste não comprovavam efetividade do treinamento assertivo: em geral os pacientes pioravam em sua assertividade. Desenvolvi, então, um novo protocolo, que retirava a ênfase em quatro sessões de treino assertivo, e introduzi a participação de um familiar, com o objetivo de estender a duração do tratamento até depois de ele ter terminado na DPA (Craske \& Barlow, 1999). Os resultados iniciais confirmam que foi uma mudança adequada. Na quinta sessão, realizada com a presença de acompanhantes, o objetivo é obter o apoio destes como aliados no processo de recuperação dos pacientes. Para esse fim, são dadas a eles as devidas explicações sobre o transtorno de pânico, tal como fora feito com os pacientes na primeira sessão. Se possível, essa explicação deve ser dada pelos próprios pacientes, a fim de verificar o entendimento destes acerca do transtorno.

Na sessão 6, realizada também com a presença de acompanhantes, o objetivo é começar a preparar as exposições situacionais que serão feitas pelos pacientes. Para tal, é explicada aos pacientes e aos acompanhantes a lógica da exposição situacional, e os acompanhantes são instruídos a respeito de como devem proceder ao acompanhar os pacientes em uma exposição. Além disso, são elaboradas hierarquias de exposição para cada paciente, listando todas as situações evitadas e organizando-as em ordem crescente de dificuldade.

Na sessão 7, realizada com a presença de acompanhantes, o objetivo é finalizar a elaboração das hierarquias de exposição e demonstrar como essa deve ser realizada. Para tanto, são revistas as hierarquias de cada um e é escolhida uma situação para se realizar uma exposição prolongada.

A sessão 8 tem como objetivos rever o que foi visto durante as sessões anteriores e preparar os pacientes para possíveis recaídas. Para tanto, são revistos os conceitos e exercícios transmitidos durante o grupo, repetindo algum se necessário, e discutida a possibilidade de recaídas futuras, buscando desconstruir alguns mitos acerca das recaídas e levar os pacientes a enxergálas sob uma perspectiva mais favorável.

Após o grupo, observa-se que os pacientes obtêm uma melhora significativa de seus sintomas e espera-se que estejam preparados para continuar seu processo de melhora sem a ajuda do terapeuta. A decisão de incluir acompanhantes no processo foi tomada justamente com o objetivo de tornar os ganhos mais duradouros e como uma forma de reduzir o tempo do tratamento, pois não é necessário que o terapeuta acompanhe os pacientes durante todas as suas exposições situacionais. Esse protocolo foi elaborado a fim de se desenvolver uma forma de tratamento eficaz que consuma o mínimo de tempo possível, dada a grande procura que existe pelos serviços da DPA. Vale lembrar que, embora o protocolo seja de curtíssimo prazo, durando apenas oito semanas, há evidências na literatura que sugerem a eficácia de protocolos desse 
tipo, ou até mesmo mais curtos, para o pânico e para a agorafobia (Deacon \& Abramowitz, 2005; Elsesser, Mosch \& Sartory, 2002).

\section{Referências}

Ayres, L. S., \& Ferreira, M. C. (1995). Para medir assertividade: construção de uma escala. Boletim CEPA, 2, 9-19.

American Psychiatric Association (2002). Manual diagnóstico eestatístico de transtornos mentais (4a. ed.; Texto revisado). São Paulo: Artmed.

Baillie, A., \& Rapee, R. (2004). Predicting who benefits from psychoeducation and self help for panic attacks. Behaviour Research and Therapy, 42 (5), 513-527.

Bandelow, B. (1995). Assessing the efficacy of treatment for panic disorder and agoraphobia. II. The Panic and Agoraphobia Scale. International Clinical Psychopharmacology, 10 (2), 73-81.

Barlow, D. H., \& Cerny, J. A. (1999) Tratamento psicológico do pânico. Porto Alegre: Artmed.

Beck, A. T., Eptein, N., Brown, G., \& Steer, R. A. (1988). An inventory for measuring anxiety: psychometric properties. Journal of Consulting and Clinical Psychological, 56, 893-897.

Beck, A. T., Ward, C. H., Mendelson, M., Mock, J., \& Erbaugh, J. (1961). An inventory for measuring depression. Archives of general Psychiatry, 4, 561-571.

Beck, J. S. (1997). Terapia cognitiva. Porto Alegre: Artmed.

Biaggio, A., Natalicio, L., \& Spielberger, C. D. (1977). Desenvolvimento da forma experimental em português do inventário de ansiedade traço-estado (IDATE) de Spielberger. Arquivos Brasileiro de Psicologia Aplicada, 29 (3), 31-44.

Chambless, D. L., Caputo, C. G., Jasin, S. E., Gracely, E. J., \& Williams, C. (1985). The mobility inventory for agoraphobia. Behaviour Research and Therapy, 23 (1), 35-44.

Chambless, D. L., Caputo, G. C., Bright, P., \& Gallagher, R. (1984). Assessment of fear in agoraphobics: the body sensations questionnaire and the agoraphobic cognitions questionnaire. Journal of Consulting and Clinical Psychology, 52 (6), 1090-1097

Chambless, D. L., Hunter, K., \& Jackson, A. (1982). Social anxiety and assertiveness: a comparison of the correlations in phobic and college student samples. Behavior Research \& Therapy, 20 (4), 403-404.

Ciconelli, R. M., Ferraz, M. B., \& Santos, W. (1998). Tradução para a língua portuguesa e validação do questionário genérico de avaliação de qualidade de vida SF-36 (Brasil SF-36). Revista Brasileira Reumatologia, 39 (3), 143 -50.
Craske, M., \& Barlow, D. (1999). Transtorno de pânico e agorafobia. In D. Barlow (Org.), Manual clínico dos transtornos psicológicos. Porto Alegre: Artmed.

Deacon, B., \& Abramowitz, J. (2005). A pilot study of two-day cognitive-behavioral therapy for panic disorder. Behaviour Research and Therapy, 44 (6), 807-817.

Derogatis L R., Lipman R. S., Covi L. (1973). SCL-90: an outpatient psychiatric rating scale - preliminary report. Psychopharmacol Bull, 9 (1), 13-28.

Di Nardo, P. A., Brown, T. A., \& Barlow, D. H. (1995). Anxiety disorders interview schedule for DSM-IV (ADIS-IV). Albany: Greywind.

Dryden, W., \& Ellis, A. (1988). Rational-Emotive Therapy. In K. S. Dobson. Handbook of cognitive-behavioural therapies. London: Hutchison.

Ellis, A. (1962). Reason and emotion in psychotherapy. New York: Lyle Stuart.

Elsesser, K., Mosch, A., \& Sartory, G. (2002). Brief psychological treatment for the relief of panic disorder. Behavioural and Cognitive Psychotherapy, 30, 502-505.

Gelder, M. G., \& Marks, I. M. (1966). Severe agoraphobia: a controlled prospective trial of behaviour therapy. British Journal of Psychiatry, 112, 309-319.

Jacobson, E. (1938). Progressiverelaxation. Chicago: University of Chicago Press.

Luthe, W. (Ed.) (1969). Autogenic therapy. New York: Grune \& Straton.

Martins, V. (2005). Seja assertivo! Rio de Janeiro: Elsevier.

Pfohl, B., Zimmerman, M., Blum, N., \& Stangl, D. (1989). Entrevista estruturada para transtornos da personalidade pelo DSM-III-R (SCID-TP). São Paulo: Escola Paulista de Medicina [mimeografado].

Rangé, B. P. (Org.) (1995). Psicoterapia comportamental e cognitiva de transtornos psiquiátricos. Campinas: Editorial Psy.

Rangé, B. P. (1996). Questionário de pânico. Manuscrito não-publicado.

Seligman, M. E. P. (1995). O que você pode e o que não pode mudar. Rio de Janeiro: Objetiva.

Wenzel, A., Sharp, I. R., Brown, G. K., Greenberg, R. L., \& Beck, A. T. (2006). Dysfunctional beliefs in panic disorder: the panic belief inventory. Behaviour Research and Therapy, 44 (6), 819-833.

Wolfe, B. E., \& Maser, J. D. (Eds.) (1994). Treatment of panic disorder: a consensus development conference. Washington, DC: American Psychiatric Press.

Recebido em: 15/12/2006

Versão final reapresentada em: 29/6/2007

Aprovado em: 26/7/2008 